\title{
Surgical Outcomes of Transpedicular Decompression with or without Global Reconstruction in Thoracic/Thoracolumbar Pott's Spine: A 7-Year Institutional Retrospective Study
}

\author{
Kalyan Kumar Varma Kalidindi ${ }^{1}$, Kuldeep Bansal ${ }^{1}$, Gourab Biswas ${ }^{2}$, Anuj Gupta ${ }^{1}$, \\ Gayatri Vishwakarma ${ }^{3}$, Vikas Tandon ${ }^{1}$, Harvinder Singh Chhabra ${ }^{1}$ \\ ${ }^{I}$ Department of Spine Service, Indian Spinal Injuries Center, New Delhi, India \\ ${ }^{2}$ Department of Orthopaedics, Guru Tej Bahadur Hospital, New Delhi, India \\ ${ }^{3}$ Department of Biostatistics, Indian Spinal Injuries Center, New Delhi, India
}

Study Design: Retrospective case-control study.

Purpose: This study aimed to analyze the radiological and clinical outcomes of transpedicular decompression in spinal tuberculosis (or Pott's spine) with and without anterior reconstruction using polyetheretherketone (PEEK) or mesh cage.

Overview of Literature: The outcomes of transpedicular decompression with and without global reconstruction in Pott's spine are insufficiently investigated. Additionally, the use of PEEK cages in Pott's spine has remained unestablished.

Methods: Using the hospital records and imaging database obtained from January 2014 to January 2020, this study retrospectively analyzed patients who underwent surgery for Pott's spine and met the eligibility criteria.

Results: This study included 230 patients with a mean \pm standard deviation age of 47.7 \pm 18.1 years (109 males, 121 females). The Visual Analog Scale score, Oswestry Disability Index, and Cobb angle were significantly improved in these patients $(p<0.001)$. Patients who underwent anterior reconstruction had a greater correction in Cobb angle postoperatively $(p=0.042)$ but also had a greater blood loss $(p=0.04)$. During the follow-up, they experienced a significant loss of correction compared with those who only underwent transpedicular decompression $(p=0.026)$. Nevertheless, patients who underwent anterior reconstruction using mesh/PEEK cages showed no significance difference in the clinical or radiological outcomes.

Conclusions: Transpedicular decompression used in the surgical management of Pott's spine showed favorable clinical and radiological outcomes. The additional use of anterior reconstruction obtained equivalent clinical outcomes but resulted in excessive blood loss. Meanwhile, the use of mesh/PEEK cage for anterior reconstruction did not affect the clinical and radiological outcomes.

Keywords: Spinal tuberculosis; Surgical decompression; Artificial implants

Received Jan 11, 2021; Revised Apr 23, 2021; Accepted Apr 26, 2021

Corresponding author: Kalyan Kumar Varma Kalidindi

Indian Spinal Injuries Center, Vasant Kunj, New Delhi, 110070, India

Tel: +91-9597732908, Fax: +91-1142255200, E-mail: issicon@isiconline.org 


\section{Introduction}

Spinal tuberculosis (TB; or Pott's spine) was once believed to affect primarily the underprivileged sections of developing countries. However, with globalization and migration of people across the world, it has now become an international concern [1]. World Health Organization estimates suggest that TB bacteria infect approximately a quarter of the world's population. According to the global TB report 2019, around 10 million people suffer from TB annually [2]. In particular, skeletal TB accounts for approximately $10 \%$ of extrapulmonary TB cases, and roughly $50 \%$ of skeletal TB cases are spinal TB [3].

Serious complications such as neurological deficit and spinal deformity are associated with spinal TB; thus, early diagnosis and management are necessary. Surgical intervention is usually indicated in spinal TB associated with neurological complications, instability, or spinal deformity. The aim of surgery in spinal TB is adequate decompression, providing stability and correcting the deformity along with correction maintenance [4].

Through traditional anterior approaches, the infective tissue can be directly accessed, and adequate decompression can be provided; however, the fixation strength is inadequate, and complications such as loss of correction or graft failure are common [5]. Though combined anterior and posterior approaches can overcome the stability issues, they carry a higher risk of morbidity because of performing two surgeries [6]. In recent years, transpedicular approaches have been popularized; by using pedicle screw constructs, adequate circumferential decompression as well as strong fixation can be established [7].

Considering that the anterior column is predominantly involved in spinal $\mathrm{TB}$, posterior instrumentation alone cannot compensate for the anterior void created because of the pathology; thus, anterior reconstruction is sometimes necessary. Titanium mesh cages, tricortical bone grafts, and polyetheretherketone (PEEK) cages are commonly used for anterior reconstruction. The use of foreign materials was previously prohibited because of the belief that biofilm formation and bacterial adherence to the material might occur [8]. However, the use of titanium cages in infections, particularly TB, has resulted in good outcomes, possibly because of the less adherence of TB bacilli than other pyogenic bacilli, such as Staphylococcus aureus, and the less tendency of titanium alloys to colonization than stainless steel [9]. According to few recent stud- ies, PEEK cages have also been used in spinal infections $[10,11]$.

In this study, we aimed to conduct an institutional retrospective clinical study to analyze the radiological and clinical outcomes of transpedicular decompression in spinal TB with and without anterior reconstruction using PEEK or mesh cages.

\section{Materials and Methods}

\section{Study design}

This study conformed to the principles of the Declaration of Helsinki. The place of study accepts retrospective studies without the approval of the institutional review board. Informed consent was obtained from all eligible patients. Using the hospital records and imaging database recorded between January 2014 and January 2020 in a tertiary care referral center, we retrospectively analyzed patients who underwent surgery for spinal TB and satisfied the eligibility criteria given below:

\section{1) Inclusion criteria}

We included adult patients who were diagnosed with spinal TB (diagnosed by histopathological or microbiological tests from tissue samples retrieved during surgery or preoperative biopsy) with thoracic/thoracolumbar region involvement, underwent surgical transpedicular decompression for spinal $\mathrm{TB}$, and had follow-up details for at least 2 years.

\section{2) Exclusion criteria}

We excluded patients with spinal TB that was not established in tissue samples through histopathological or microbiological tests, those with multidrug-resistant TB, those without surgical decompression history, those with decompression experience through approaches other than the transpedicular approach, those with revision surgery, and/or those with missing follow-up details.

Details such as age, sex, level of involvement, number of vertebrae involved, Visual Analog Scale (VAS; preoperative, postoperative, and follow-up), Oswestry Disability Index (ODI; preoperative, postoperative, and follow-up), neurological status (preoperative and follow-up grading using the American Spinal Injury Association Impairment Scale [AIS]), technique of anterior reconstruction, amount of blood loss, duration of surgery, and Cobb angle 
(preoperative, postoperative, and follow-up) were collected from the database.

\section{Statistical analysis}

Summarized measurement results are presented as mean and standard deviation (SD) (minimum-maximum) for continuous variables and as numbers and percentages for categorical variables. Significant associations between the study parameters of the categorical scale were examined by chi-square/Fisher exact test. For the continuous scale, the significance of parameters between two groups was analyzed by independent samples $t$-test/Mann-Whitney $U$-test as per data distribution. All statistical data were analyzed using the IBM SPSS Statistics for Windows ver. 25.0 (IBM Corp., Armonk, NY, USA). Statistical significance was set at $5 \%$ level.

\section{Surgical details}

We followed the middle path regimen proposed by Tuli $[12,13]$. We performed transpedicular decompression in patients with rapidly deteriorating neurology, neurological deficit refractory to 6-week antitubercular therapy (ATT), significant kyphosis progression, instability, and/ or no response to ATT in 3-6 months [14].

All the patients, except those with complete spinal cord injury (AIS-A), underwent surgery under multimodal neuromonitoring guidance, and they were operated by a posterior-only approach using a standard midline incision. The periosteal muscle was elevated, and the facet joints were exposed. Under fluoroscopic guidance, pedicle screws were placed in a standard fashion, extending 1 or 2 levels above and below the pathological levels depending on the number of vertebrae involved and extent of collapse. After a temporary connecting rod was placed on the opposite side, transpedicular decompression was performed; Fig. 1 describes the stages of transpedicular decompression. Thereafter, the transverse process and a rib (approximately 3-4 $\mathrm{cm}$ ) along with the rib head (costotransversectomy) on the decompression side were removed. Finally, the pedicle was removed using rongeurs and burr (pediculectomy), and the spinal cord was decompressed (Fig. 1). If necessary, the same process was performed on the opposite side of the lesion. After adequate spinal cord decompression and anterior debridement, anterior reconstruction was performed as necessary,

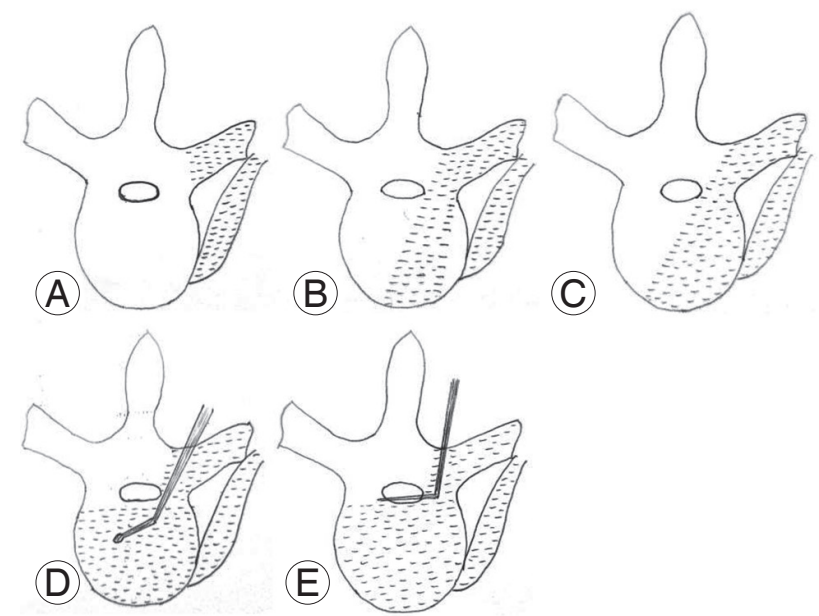

Fig. 1. Illustrations showing the stages of decompression in Pott's spine. The area shaded in light grey depicts the area which can be decompressed in that stage. Through a midline posterior approach, subperiosteal dissection was done to expose the bony structures. Pedicle screw fixation was done at the desired levels above and below the affected level. Laminectomy/laminotomy was performed if necessary. The transverse process and rib head were exposed and removed (costotransversectomy). (A) Costotransversectomy: Paravertebral abscesses can be decompressed at this stage. (B) Transpedicular decompression: Using curettes/probes, the cancellous bone of the pedicle is removed and the vertebral body reached. Obtaining a sample for biopsy/draining pus from the vertebral body/paradiscal area is possible during this stage. (C) Pediculectomy: Removal of the lateral wall of the pedicle allows access to the lateral and anterior vertebral body. The lateral spinal canal can be decompressed at this stage. The inferior and medial walls of the pedicles are removed at the end. (D) Anterior reconstruction: After removal of the pedicle, the superior disc space can be easily approached. Discectomy and fusion can also be performed. If there is gross destruction of vertebral body requiring corpectomy, burr/curettes can be used to remove the cancellous bone of the vertebral body. (E) Corpectomy: After vertebral body decancellation, the posterior vertebral wall is finally removed using a Kerrison rongeur/punch decompressing the anterior spinal canal.

using mesh/PEEK cages filled with an autologous bone graft extracted from the excised rib/posterior elements. If anterior reconstruction was deemed unnecessary because of minimal void, only compression of the involved vertebrae with use of a local autologous bone graft was performed. Meanwhile, the kyphosis was gradually corrected by compression-distraction techniques. Final tightening was done, drains were placed, and the wound was closed in layers. Resected specimens underwent histopathological and microbiological tests. Figs. 2-4 provide representative images.

Through a preoperative work-up (magnetic resonance imaging and computed tomography), the amount of bone damage and the possible technique for reconstruction were determined. However, most of the time, the decision was made intraoperatively. In an extensive anterior bone destruction, a mesh cage may be necessary. If the end plates were reasonably healthy/sclerotic, PEEK cage would 

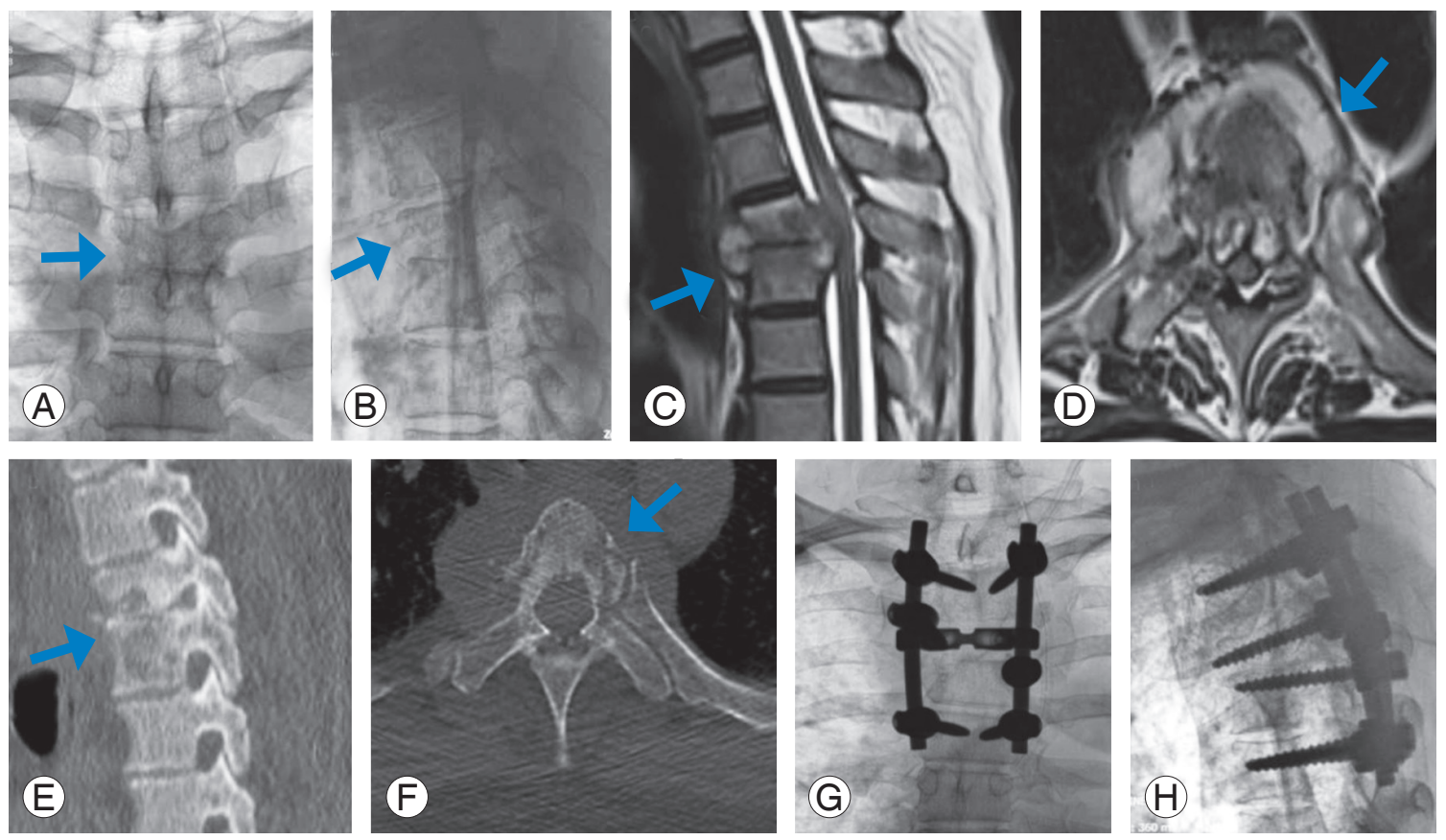

Fig. 2. Preoperative $X$-rays $(\mathbf{A}, \mathbf{B})$, magnetic resonance imaging (C, D), computed tomography scan $(\mathbf{E}, \mathbf{F})$, and postoperative $X$-rays $(\mathbf{G}, \mathbf{H})$ of a patient who underwent posterior stabilization and transpedicular decompression by pediculectomy without anterior reconstruction. The arrows point the area involved by the pathology.
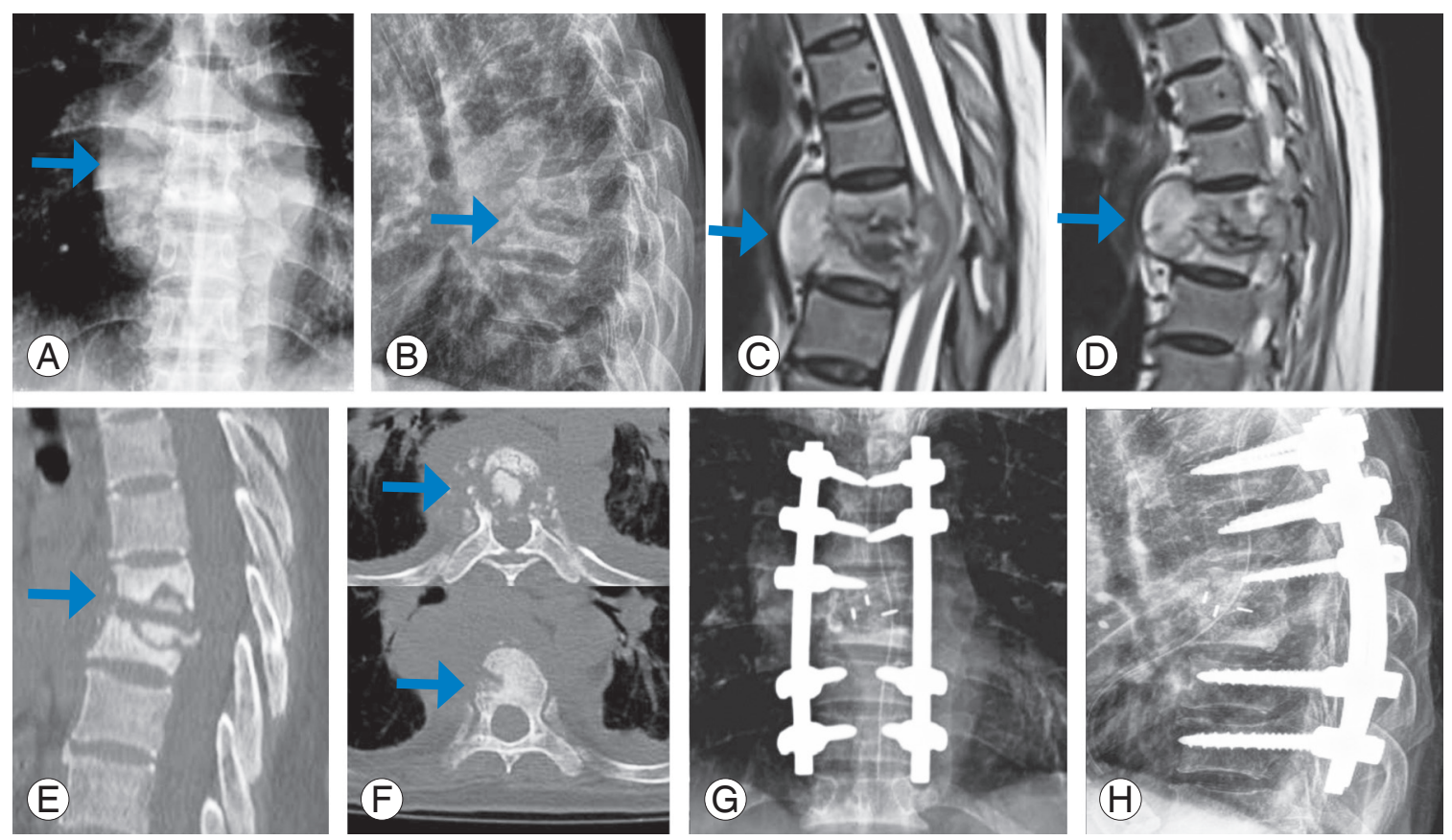

Fig. 3. Preoperative $X$-rays $(\mathbf{A}, \mathbf{B})$, magnetic resonance imaging $(\mathbf{C}, \mathbf{D})$, computed tomography scan $(\mathbf{E}, \mathbf{F})$, and postoperative $\mathbf{X}$-rays $(\mathbf{G}, \mathbf{H})$ of a patient who underwent posterior stabilization and transpedicular decompression by pediculectomy with anterior reconstruction using polyetheretherketone cage. The arrows point the area involved by the pathology. 

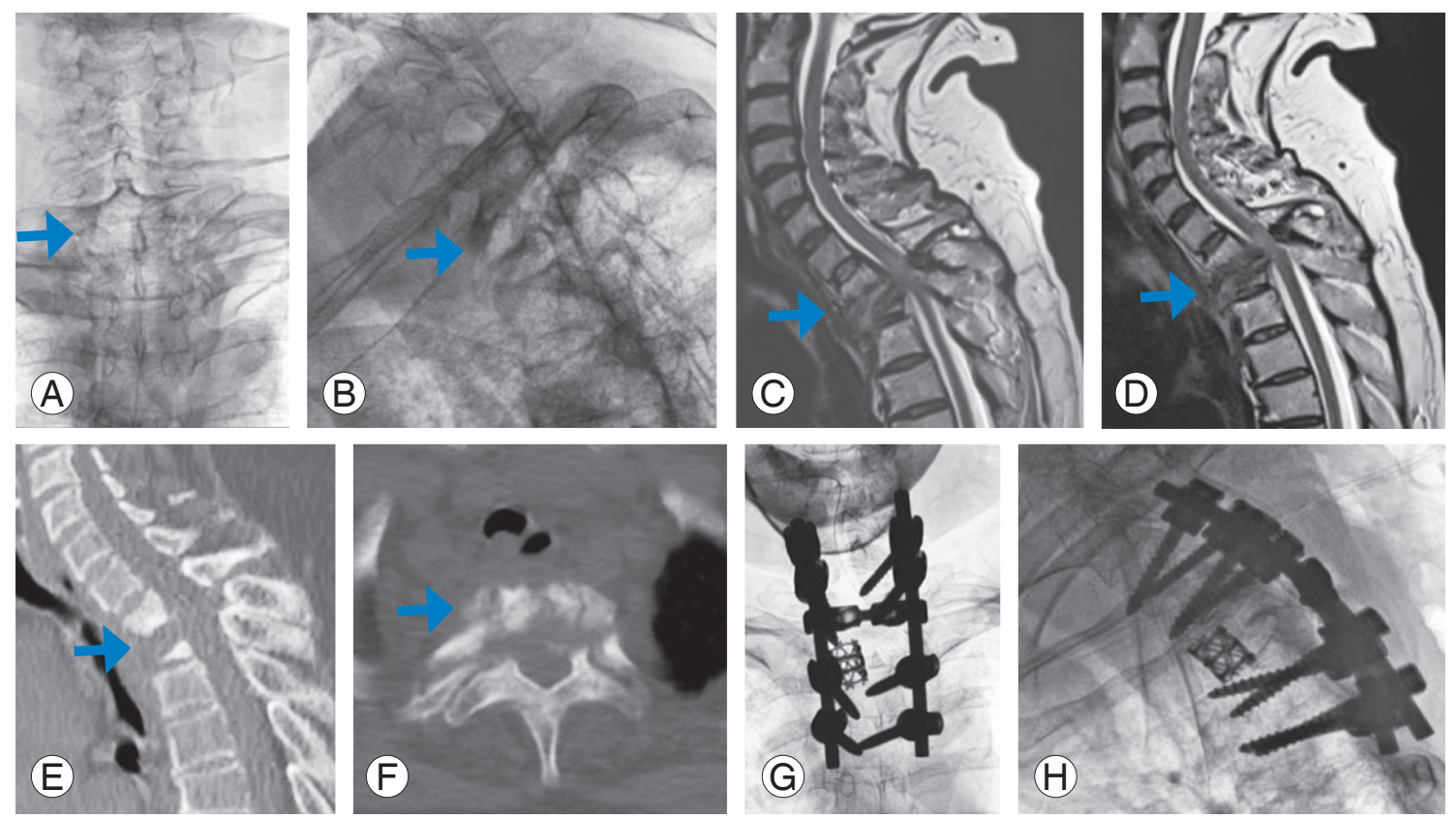

Fig. 4. Preoperative $X$-rays $(\mathbf{A}, \mathbf{B})$, magnetic resonance imaging $(\mathbf{C}, \mathbf{D})$, computed tomography scan $(\mathbf{E}, \mathbf{F})$ and postoperative $X$-rays $(\mathbf{G}, \mathbf{H})$ of a patient who underwent posterior stabilization and transpedicular decompression by pediculectomy followed by corpectomy and anterior reconstruction using mesh cage. The arrows point the area involved by the pathology.

be sufficient. The technique of transpedicular decompression generally does not alter the anterior bony construct.

\section{Results}

This study included 230 patients with a mean \pm SD age of $47.7 \pm 18.1$ years ( 109 males and 121 females). Involvement of the thoracic region (T2-T9) and thoracolumbar region (T10-L2, including T9-T10 disc space) was found in 134 (58\%) and 96 (42\%) patients, respectively. Two vertebrae were affected in most of the patients (190 patients), while three, four, five, and six vertebrae were involved in 30 , three, six, and one patient(s), respectively. We found 16 cases of drug resistance. For the preoperative neurological status, AIS-C was found in most patients (133 patients), followed by AIS-D in 33, AIS-A in 28, and AIS-B in 15 patients; meanwhile, 21 patients remained normal neurologically. Postoperatively, the neurological status was improved overall (AIS-C, AIS-D, and AIS-E in 42, 90, and 98 patients, respectively). The mean \pm SD blood loss was $336.6 \pm 85.1 \mathrm{~mL}$, and the mean duration of surgery was $2.4 \pm 0.5$ hours (Table 1). Table 2 compares the preoperative and postoperative clinical and radiological parameters. Furthermore, VAS, ODI, and Cobb angle were significantly improved in all patients.

\section{Comparison between patients who underwent trans- pedicular decompression and those who underwent anterior reconstruction in addition}

Table 1 compares the variables between the groups. Patients who underwent transpedicular decompression plus anterior reconstruction were younger than those who underwent transpedicular decompression alone $(p=0.005)$. However, blood loss was significantly higher in the anterior reconstruction group than in the other group $(p=0.04)$. The other variables were not significantly different between the two groups. The anterior reconstruction group also had a greater correction in Cobb angle postoperatively than the other group ( $p=0.042$ ). However, during the follow-up, the anterior reconstruction group had a significant loss of correction than the other group $(p=0.026)$; nonetheless, the preoperative $(p=0.251)$ and postoperative $(p=0.781)$ Cobb angles were not significantly different between the two groups. Considering interobserver and intraobserver variability, radiologic differences were not clinically meaningful between the two groups. Perhaps, the differences resulted from a selection bias, given that patients with severe diseases are likely to undergo an anterior reconstruction. 
Table 1. Comparison of variables between patients who underwent anterior reconstruction versus those who did not

\begin{tabular}{|c|c|c|c|}
\hline \multirow{2}{*}{ Characteristic } & \multicolumn{2}{|c|}{ Anterior reconstruction } & \multirow{2}{*}{$p$-value } \\
\hline & Not done $(n=147)$ & Mesh/PEEK used ( $n=83$ ) & \\
\hline Age (yr) & $50.21 \pm 17.5$ & $43.40 \pm 18.5$ & $0.005^{\mathrm{a}}$ \\
\hline \multicolumn{4}{|l|}{ Gender } \\
\hline Male & $73(49.7)$ & $36(43.4)$ & $0.359^{b}$ \\
\hline Female & $74(50.3)$ & $47(56.6)$ & \\
\hline \multicolumn{4}{|l|}{ Level } \\
\hline Thoracic & 85 (57.8) & $49(59.0)$ & $0.858^{b}$ \\
\hline Thoracolumbar & $62(42.2)$ & $34(41.0)$ & \\
\hline \multicolumn{4}{|l|}{ Preop neurological status (AIS) } \\
\hline A & $14(9.5)$ & $14(16.9)$ & \\
\hline B & $11(7.5)$ & $4(4.8)$ & \\
\hline C & $82(55.8)$ & $51(61.4)$ & $0.219^{b}$ \\
\hline D & $25(17.0)$ & $8(9.6)$ & \\
\hline E & $15(10.2)$ & $6(7.2)$ & \\
\hline \multicolumn{4}{|l|}{ Postop neurological status (AIS) } \\
\hline C & $25(17.0)$ & $17(20.5)$ & \\
\hline $\mathrm{D}$ & $55(37.4)$ & $35(42.2)$ & $0.472^{b}$ \\
\hline E & $67(45.6)$ & $31(37.3)$ & \\
\hline No. of vertebra & $2.27 \pm 0.67(2-6)$ & $2.19 \pm 0.48(2-5)$ & $0.363^{\mathrm{a}}$ \\
\hline Preop 0DI & $80.55 \pm 7.6$ & $80.39 \pm 7.6$ & $0.874^{\mathrm{a}}$ \\
\hline Postop ODI & $46.06 \pm 9.9$ & $46.29 \pm 11.3$ & $0.874^{\mathrm{a}}$ \\
\hline Blood loss (mL) & $327.96 \pm 75.7$ & $351.93 \pm 98.2$ & $0.040^{\mathrm{a}}$ \\
\hline Duration of surgery (hr) & $2.35 \pm 0.46$ & $2.43 \pm 0.51$ & $0.205^{\mathrm{a}}$ \\
\hline Preop Cobb angle $\left({ }^{\circ}\right)$ & $18.95 \pm 6.0$ & $19.87 \pm 8.1$ & $0.327^{\mathrm{a}}$ \\
\hline Postop Cobb angle $\left({ }^{\circ}\right)$ & $10.60 \pm 3.8$ & $10.05 \pm 4.4$ & $0.318^{\mathrm{a}}$ \\
\hline Final Cobb angle $\left({ }^{\circ}\right)$ & $12.34 \pm 3.4$ & $12.44 \pm 4.5$ & $0.859^{\mathrm{a}}$ \\
\hline Preop VAS & $8.14 \pm 0.8$ & $8.27 \pm 0.8$ & $0.251^{\mathrm{a}}$ \\
\hline Postop VAS & $2.83 \pm 1.3$ & $2.78 \pm 1.2$ & $0.781^{\mathrm{a}}$ \\
\hline Difference in ODI & $-34.49 \pm 11.56$ & $-34.1 \pm 11.94$ & 0.809 \\
\hline Difference in VAS & $-5.31 \pm 1.51$ & $-5.48 \pm 1.43$ & 0.408 \\
\hline Difference in (preop-postop) Cobb angle $\left(^{\circ}\right)$ & $-8.34 \pm 4.61$ & $-9.82 \pm 6.23$ & 0.042 \\
\hline Difference in (follow-up-postop) Cobb angle $\left(^{\circ}\right.$ ) & $1.74 \pm 1.51$ & $2.39 \pm 2.86$ & 0.026 \\
\hline
\end{tabular}

Values are presented as mean \pm SD, number $(\%)$, or mean \pm SD (range). Bold letter represents significant $p$-value at $5 \%$ level.

SD, standard deviation; PEEK, polyetheretherketone; Preop, preoperative; Postop, postoperative; AIS, American Spinal Injury Association Impairment Scale; ODI, Oswestry Disability Index; VAS, Visual Analog Scale.

${ }^{a}$ By Student $t$-test for two independent samples. ${ }^{b} B y$ chi-square test.

\section{Comparison between mesh and PEEK cages in patients who underwent anterior reconstruction}

Table 3 compares the variables between the groups. The PEEK cage was preferred for thoracolumbar Pott's spine, whereas the mesh cage was preferred for thoracic Pott's spine $(p=0.008)$. The clinical outcomes (improvement in VAS/ODI) or radiological outcomes (improvement in Cobb angle) were not significantly different between the two groups. During the follow-up, the correction of Cobb angle did not differ between the two groups. 
Table 2. Comparison of preoperative and postoperative clinical and radiological parameters of patients who underwent transpedicular decompression for Pott's spine

\begin{tabular}{lccc} 
Variable & Preoperative & Postoperative & $p$-value \\
\hline Oswestry Disability Index & $80.5 \pm 7.6$ & $46.1 \pm 10.4$ & $<0.001$ \\
Visual Analog Scale & $8.2 \pm 0.8$ & $2.8 \pm 1.2$ & $<0.001$ \\
\hline Cobb angle $\left(^{\circ}\right)$ & $19.3 \pm 6.8$ & $10.4 \pm 4.0$ & $<0.001$ \\
\hline
\end{tabular}

Values are presented as mean \pm standard deviation.

\section{Discussion}

Our technique, that is, global reconstruction through a posterior-only approach, involved a costotransversectomy and an extrapleural approach to the anterior column, thereby circumferentially decompressing the cord as well as placing a structural support anteriorly. However, stud-

Table 3. Comparison of variables between patients who underwent anterior reconstruction using mesh and PEEK cages

\begin{tabular}{|c|c|c|c|}
\hline \multirow{2}{*}{ Characteristic } & \multicolumn{2}{|c|}{ Anterior reconstruction } & \multirow{2}{*}{$p$-value } \\
\hline & Mesh $(n=53)$ & PEEK $(n=30)$ & \\
\hline Age (yr) & $41.81 \pm 18.9$ & $45.97 \pm 17.7$ & $0.328^{\mathrm{al}}$ \\
\hline \multicolumn{4}{|l|}{ Gender } \\
\hline Male & $28(52.8)$ & $8(26.7)$ & $0.021^{b}$ \\
\hline Female & $25(47.2)$ & $22(73.3)$ & \\
\hline \multicolumn{4}{|l|}{ Level } \\
\hline Thoracic & $37(69.8)$ & $12(40.0)$ & $0.008^{b \mid}$ \\
\hline Thoracolumbar & $16(30.2)$ & $18(60.0)$ & \\
\hline \multicolumn{4}{|l|}{ Preop neurological status (AIS) } \\
\hline A & $8(15.1)$ & $6(20.0)$ & \\
\hline B & $2(3.8)$ & $2(6.7)$ & \\
\hline C & $34(64.2)$ & $17(56.7)$ & $0.762^{b l}$ \\
\hline $\mathrm{D}$ & $6(11.3)$ & $2(6.7)$ & \\
\hline $\mathrm{E}$ & $3(5.7)$ & $3(10.0)$ & \\
\hline \multicolumn{4}{|l|}{ Postop neurological status (AIS) } \\
\hline C & $10(18.9)$ & $7(23.3)$ & \\
\hline $\mathrm{D}$ & 28 (52.8) & $7(23.3)$ & $0.025^{b}$ \\
\hline $\mathrm{E}$ & $15(28.3)$ & $16(53.3)$ & \\
\hline No. of vertebra & $2.19 \pm 0.40(2-3)$ & $2.20 \pm 0.61(2-5)$ & 0.919 \\
\hline Preop ODI & $80.91 \pm 7.3$ & $79.47 \pm 8.1$ & 0.409 \\
\hline Postop ODI & $46.77 \pm 10.5$ & $45.43 \pm 12.8$ & 0.608 \\
\hline Blood loss (mL) & $363.21 \pm 109.4$ & $332.00 \pm 71.8$ & 0.166 \\
\hline Duration of surgery (hr) & $2.49 \pm 0.53$ & $2.33 \pm 0.46$ & 0.179 \\
\hline Preop Cobb angle $\left({ }^{\circ}\right)$ & $20.83 \pm 8.1$ & $18.17 \pm 4.6$ & 0.154 \\
\hline Postop Cobb angle $\left({ }^{\circ}\right)$ & $11.17 \pm 4.6$ & $8.07 \pm 3.0$ & $<0.001$ \\
\hline Final Cobb angle $\left({ }^{\circ}\right)$ & $13.25 \pm 4.9$ & $11.01 \pm 3.3$ & 0.027 \\
\hline Preop VAS & $8.21 \pm 0.7$ & $8.37 \pm 0.9$ & 0.386 \\
\hline Difference in ODI & $-34.13 \pm 11.76$ & $-34.03 \pm 12.44$ & 0.971 \\
\hline Difference in VAS & $-5.36 \pm 1.51$ & $-5.7 \pm 1.29$ & 0.3 \\
\hline Difference in (preop-postop) Cobb angle $\left(^{\circ}\right)$ & $-9.66 \pm 6.16$ & $-10.1 \pm 6.43$ & 0.759 \\
\hline Difference in (follow-up-postop) Cobb angle $\left(^{\circ}\right)$ & $2.08 \pm 2.72$ & $2.94 \pm 3.06$ & 0.186 \\
\hline
\end{tabular}

Values are presented as mean $\pm S D$, number $(\%)$, or mean $\pm S D$ (range). Bold letter represents significant $p$-value at $5 \%$ level.

SD, standard deviation; PEEK, polyetheretherketone; Preop, preoperative; Postop, postoperative; AIS, American Spinal Injury Association Impairment Scale; ODI, Oswestry Disability Index; VAS, Visual Analog Scale.

${ }^{a}$ By Student $t$-test for two independent samples. ${ }^{b}$ By chi-square test. 
ies on the surgical outcomes of these procedures in spinal TB are limited. Meanwhile, we observed that transpedicular decompression is safe and effective for managing spinal TB. In addition, anterior reconstruction resulted in a greater correction of the kyphosis than transpedicular decompression or posterior stabilization alone. The type of anterior reconstruction (using mesh or PEEK cage) did not affect the radiological or clinical outcomes.

Prior to the advent of ATT, surgical debridement was the mainstay of Pott's spine management. When ATT began, majority of the cases evidently did not require surgery [14]. Many surgeons reported excellent results after administering anti-TB drugs alone and performing surgery to patients who were refractory to drugs or those who had complications [13]. The surgical approaches have also evolved over the years. Pott's spine usually spares the posterior column; hence, laminectomy is contraindicated for anterior spondylodiscitis. Anterolateral extrapleural and transpleural approaches have been applied for Pott's spine, but they exhibit approach-related complications. Meanwhile, the transpedicular approach allows for circumferential decompression along with the fixation of a strong three-column pedicle screw construct [7].

Zhang et al. [15] observed an improved neurological status in all 14 patients operated using this technique. They also found that the thoracic kyphotic angles were significantly improved postoperatively and at follow-up. D'souza et al. [16] also reported significant improvement in the kyphotic angles of all 21 patients with spinal TB; the VAS and neurological status were also improved in all patients. In 2018, Liu et al. [17] examined 66 patients who underwent either a short- or long-segment fusion along with transpedicular decompression; after a 5-year follow-up, all of the patients were completely cured, and they showed significant improvement in neurological status and VAS pain scores at the final follow-up. In 2019, Waliullah et al. [18] found significantly improved VAS and ODI scores on follow-up and a neurological recovery in 20 out of 23 patients with spinal TB. Moreover, Jain et al. [4] investigated 47 patients with thoracic or thoracolumbar TB who underwent transpedicular decompression and instrumented fusion. They found that the procedure was safe and effective, with improvement in clinical and radiological outcomes. The findings of our study agree with these previous studies. However, all these previous studies had a small number of patients. In addition, the results of anterior reconstruction using PEEK/mesh cages were not separately analyzed in these studies.

Titanium mesh cages can be used in spinal infections to reconstruct anterior defects [9,19-22]. However, the use of PEEK cages has not yet gained wide acceptance. Our results showed that anterior reconstruction using either titanium mesh cages or PEEK cages resulted in better radiological outcomes and had similar functional outcomes to those with no anterior reconstruction.

Furthermore, kyphosis was improved through anterior reconstruction, but a significant loss of correction was observed during follow-up. Previous studies also reported a considerable loss of correction after anterior fusion $[23,24]$. Nevertheless, the mean loss of correction was lesser in our study than in the previous studies by Moon et al. [25] and Zhao et al. [26].

With regard to study strengths, our study has the largest cohort of patients who underwent transpedicular decompression and anterior reconstruction in the published literature. Additionally, our study is the first to compare the results of transpedicular decompression with and without reconstruction and also the first to report a series of patients with thoracolumbar Pott's spine who underwent anterior reconstruction using PEEK cages.

Conversely, our study also has limitations. First, it is retrospective in nature. Second, anterior reconstruction in addition to posterior instrumentation and transpedicular decompression was possibly performed in patients who had severe kyphosis, involvement of multiple segments, or gross destruction of vertebral bodies. Third, selection bias was also likely.

\section{Conclusions}

Transpedicular decompression used in the surgical management of Pott's spine led to favorable clinical and radiological outcomes; the additional use of anterior reconstruction resulted in equivalent clinical outcomes, though excessive blood loss occurred; nonetheless, no clinically meaningful radiologic differences were found between the two groups. Meanwhile, the use of mesh/PEEK for anterior reconstruction did not affect the clinical and radiological outcomes.

\section{Conflict of Interest}

No potential conflict of interest relevant to this article was reported. 


\section{References}

1. Rajasekaran S, Soundararajan DC, Shetty AP, Kanna RM. Spinal tuberculosis: current concepts. Global Spine J 2018;8(4 Suppl):96S-108S.

2. World Health Organization. Global tuberculosis report: executive summary [Internet]. Geneva: World Health Organization; 2019 [cited 2020 Sep 19]. Available from: https://www.who.int/tb/publications/global_report/ GraphicExecutiveSummary.pdf.

3. Tuli SM. Severe kyphotic deformity in tuberculosis of the spine. Int Orthop 1995;19:327-31.

4. Jain A, Jain RK, Kiyawat V. Evaluation of outcome of transpedicular decompression and instrumented fusion in thoracic and thoracolumbar tuberculosis. Asian Spine J 2017;11:31-6.

5. Benli IT, Kaya A, Acaroglu E. Anterior instrumentation in tuberculous spondylitis: is it effective and safe? Clin Orthop Relat Res 2007;460:108-16.

6. Chen WJ, Wu CC, Jung CH, Chen LH, Niu CC, Lai PL. Combined anterior and posterior surgeries in the treatment of spinal tuberculous spondylitis. Clin Orthop Relat Res 2002;(398):50-9.

7. Lee SH, Sung JK, Park YM. Single-stage transpedicular decompression and posterior instrumentation in treatment of thoracic and thoracolumbar spinal tuberculosis: a retrospective case series. J Spinal Disord Tech 2006;19:595-602.

8. Ha KY, Chung YG, Ryoo SJ. Adherence and biofilm formation of Staphylococcus epidermidis and Mycobacterium tuberculosis on various spinal implants. Spine (Phila Pa 1976) 2005;30:38-43.

9. Fayazi AH, Ludwig SC, Dabbah M, Bryan Butler R, Gelb DE. Preliminary results of staged anterior debridement and reconstruction using titanium mesh cages in the treatment of thoracolumbar vertebral osteomyelitis. Spine J 2004;4:388-95.

10. Tschöke SK, Fuchs H, Schmidt O, Gulow J, von der Hoeh NH, Heyde CE. Single-stage debridement and spinal fusion using PEEK cages through a posterior approach for eradication of lumbar pyogenic spondylodiscitis: a safe treatment strategy for a detrimental condition. Patient Saf Surg 2015;9:35.

11. Li Z, Wu W, Chen R, Huang Y, Chen X, Lin J. Could Allograft bones combined with poly-ether-etherketone cages or titanium mesh cages be an alternative grafting method in the management of cervical spi- nal tuberculosis? World Neurosurg 2019;128:e653-9.

12. Tuli SM. Results of treatment of spinal tuberculosis by "middle-path" regime. J Bone Joint Surg Br 1975;57:13-23.

13. Tuli SM. Historical aspects of Pott's disease (spinal tuberculosis) management. Eur Spine J 2013;22 Suppl 4(Suppl 4):529-38.

14. Khanna K, Sabharwal S. Spinal tuberculosis: a comprehensive review for the modern spine surgeon. Spine J 2019;19:1858-70.

15. Zhang H, Sheng B, Tang M, et al. One-stage surgical treatment for upper thoracic spinal tuberculosis by internal fixation, debridement, and combined interbody and posterior fusion via posterior-only approach. Eur Spine J 2013;22:616-23.

16. D’souza AR, Mohapatra B, Bansal ML, Das K. Role of posterior stabilization and transpedicular decompression in the treatment of thoracic and thoracolumbar TB: a retrospective evaluation. Clin Spine Surg 2017;30:E1426-33.

17. Liu Z, Zhang P, Zeng H, Xu Z, Wang X. A comparative study of single-stage transpedicular debridement, fusion, and posterior long-segment versus shortsegment fixation for the treatment of thoracolumbar spinal tuberculosis in adults: minimum five year follow-up outcomes. Int Orthop 2018;42:1883-90.

18. Waliullah S, Kumar V, Rastogi D, Srivastava RN. Efficacy of transpedicular decompression in spinal tuberculosis. Orthop Proc 2019;101-B(SUPP_3):13.

19. Robinson Y, Tschoeke SK, Kayser R, Boehm H, Heyde CE. Reconstruction of large defects in vertebral osteomyelitis with expandable titanium cages. Int Orthop 2009;33:745-9.

20. Christodoulou AG, Givissis P, Karataglis D, Symeonidis PD, Pournaras J. Treatment of tuberculous spondylitis with anterior stabilization and titanium cage. Clin Orthop Relat Res 2006;444:60-5.

21. Ruf M, Stoltze D, Merk HR, Ames M, Harms J. Treatment of vertebral osteomyelitis by radical debridement and stabilization using titanium mesh cages. Spine (Phila Pa 1976) 2007;32:E275-80.

22. Kuklo TR, Potter BK, Bell RS, Moquin RR, Rosner MK. Single-stage treatment of pyogenic spinal infection with titanium mesh cages. J Spinal Disord Tech 2006;19:376-82.

23. Rajasekaran S, Soundarapandian S. Progression of kyphosis in tuberculosis of the spine treated by ante- 
rior arthrodesis. J Bone Joint Surg Am 1989;71:131423.

24. Bailey HL, Gabriel M, Hodgson AR, Shin JS. Tuberculosis of the spine in children: operative findings and results in one hundred consecutive patients treated by removal of the lesion and anterior grafting. J Bone Joint Surg Am 1972;54:1633-57.
25. Moon MS, Woo YK, Lee KS, Ha KY, Kim SS, Sun DH. Posterior instrumentation and anterior interbody fusion for tuberculous kyphosis of dorsal and lumbar spines. Spine (Phila Pa 1976) 1995;20:1910-6.

26. Zhao H, Weng X, Shen J, Ye Q, Qiu G, Li S. Application of internal fixation in the treatment for tuberculosis of the spine. Chin Med Sci J 1994;9:179-82. 